\title{
Multi-objective Fuzzy-optimization of Crowbar Resistances for the Low-Voltage Ride-through of Doubly Fed Induction Wind Turbine Generation Systems
}

\author{
Wenjuan Zhang ${ }^{\dagger}$, Haomiao Ma**, Junli Zhang*, Lingling Chen ${ }^{* * *}$, and Yang Qu ${ }^{*}$ \\ ${ }^{+*}$ Department of Electrical Engineering, Baoji University of Arts and Sciences, Shaanxi, China \\ ${ }^{* *}$ College of Automation and Information Engineering, Xi'an University of Technology, Shaanxi, China \\ ${ }^{* * *} 94816$ troop, China
}

\begin{abstract}
This study investigates the multi-objective fuzzy optimization of crowbar resistance for the doubly fed induction generator (DFIG) low-voltage ride-through (LVRT). By integrating the crowbar resistance of the crowbar circuit as a decision variable, a multi-objective model for crowbar resistance value optimization has been established to minimize rotor overcurrent and to simultaneously reduce the DFIG reactive power absorbed from the grid during the process of LVRT. A multi-objective genetic algorithm (MOGA) is applied to solve this optimization problem. In the proposed GA, the value of the crowbar resistance is represented by floating-point numbers in the GA population. The MOGA emphasizes the non-dominated solutions and simultaneously maintains diversity in the non-dominated solutions. A fuzzy-set-theory-based is employed to obtain the best solution. The proposed approach has been evaluated on a 3 MW DFIG LVRT. Simulation results show the effectiveness of the proposed approach for solving the crowbar resistance multi-objective optimization problem in the DFIG LVRT.
\end{abstract}

Key words: Crowbar resistance, Doubly-fed induction generator (DFIG), Genetic algorithm (GA), Low voltage ride through (LVRT), Multi-objective fuzzy optimization, Objective functions

\section{INTRODUCTION}

In the past few decades, the utilization of doubly fed induction generators (DFIG) has increased significantly due to their advantages such as variable-speed-constant-frequency (VSCF) operation, decoupled control of the active and reactive powers, and availability of partial-scale converters [1]. However, since the stator of a DFIG is directly connected to the grid, this promising wind generator technology is vulnerable to grid disturbances, especially to voltage sag faults [2]. A grid voltage sag imposed at the connection point

Manuscript received Nov. 6, 2014; accepted Mar. 4, 2015

Recommended for publication by Associate Editor Hyung-Min Ryu.

†CorrespondingAuthor:zhangwj19811130@163.com

Tel: +86-15291778167, Fax: +86-0917-3364262, Baoji University of Arts and Sciences

${ }^{* *}$ Automation \& Information Engineering College, Xi'an University of Technology, China

${ }^{* * *} 94816$ troop, China of a DFIG to the grid could easily induce a DFIG rotor overcurrent, DC-link overvoltage, and torque oscillations that could lead to the destruction of the rotor-side converter, the DC-link capacitor, and other mechanical parts, respectively [3]. Thus, it is desirable that wind turbines remain connected to the grid and actively contribute to the system stability during and after grid voltage sag faults and disturbances. This ability of wind turbines is termed low-voltage ride-through (LVRT) [4], [5].

One effective way to make a DFIG capable of LVRT is to equip it with an appropriate crowbar protection circuit in the rotor side of the DFIG. However, since the transient process of the DFIG is owe damped; this will result in the grid voltage becoming lower, because when the crowbar is in operation, the insulated-gate bipolar transistors (IGBTs) of the converters will quit, and the DFIG behaves like a squirrel-cage induction machine, absorbing a large amount of 
reactive power from the grid [6]. In addition, to select a reasonable value for the crowbar resistance is important. The larger the resistance, the faster the attenuation of the transient components. However, a larger resistance may cause rotor-side overvoltage and may also damage the rotor-side converter.

A good amount of literature is available on the transient characteristics and crowbar resistance design aspects of DFIGs. In [7], Niiranen analyzes the DFIG equivalent circuit and points out that an appropriate crowbar resistance is helpful for LVRT. In addition, [8] demonstrates that a detailed dynamic representation of the converter circuitry is necessary to investigate the impact of various controls on DFIG performance. Morren reports the short-circuit maximum current and short capacity of the DFIG, and the value range of the crowbar resistance is approximately calculated in [6]. In [9], the short circuit current analytical expression is given and the decay time constant is analyzed after the crowbar protection is put into operation. In [10], based on a linear model of the maximum short-circuit current, a crowbar resistance design method is put forward that considers the DC bus clamping effect.

The aforementioned studies provide references for the design of the crowbar circuit. However, many of these studies have two limitations. First, the crowbar resistance is strictly confined by the safety range of the rotor current and voltage. In the case of optimization design by the common method, the constraints are deemed as "rigid." In addition, considering that the constraints are obtained from the point of view of safe service of the double fed converter, when a crowbar resistance value is selected on the constraint's boundary, the system works on the boundary between the safe area and the dangerous area. As a result of such a design, changes to the DFIG parameters caused by heating are likely to trigger the protection operation of the DFIG, or even lead to the destruction of the converter. Second, the existing design of the crowbar resistance merely considers how to keep rotor current and voltage within reasonable ranges, while overlooking many other properties of LVRT. For example, when the crowbar is in operation, the DFIG absorbs reactive power from the grid, leading to a further drop in the grid voltage. This is harmful to the recovery of the grid voltage. It is worth noting that the ability of the DFIG to absorb reactive power depends on the value of the crowbar resistance. Hence, the design of the crowbar resistance should take into account LVRT, which is a multi-objective fuzzy optimization problem.

Based on this fact, this paper proposes a method of using fuzzy sets to describe the crowbar resistance value range, and adopts a multi-objective genetic algorithm in order to optimize the value of the crowbar resistance. The optimized crowbar resistance can provide the best compromise solution during the process of LVRT. This also avoids that the value of the crowbar resistance be taken on the constraint boundary.

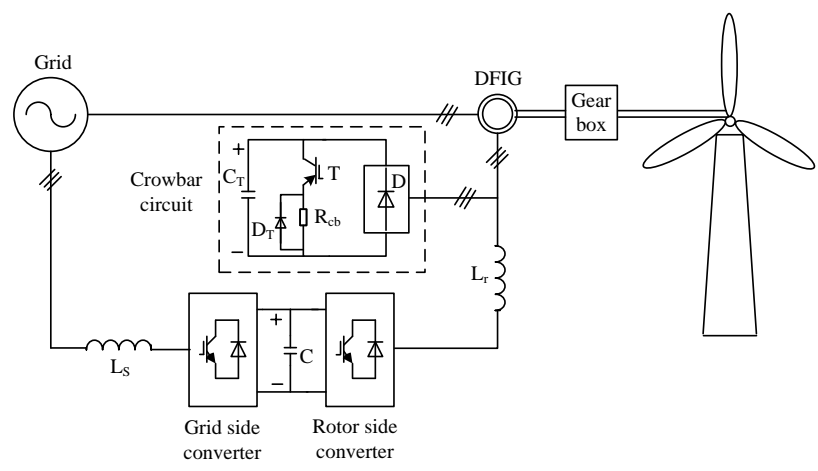

Fig. 1. DFIG crowbar protection in the rotor circuit.

These considerations will improve the ability of the DFIG in terms of LVRT and enhance the safety of the system. This paper is organized as follows. In Section 2, the behavior of the DFIG before and after grid faults is analyzed. In Section 3, the proposed multi-objective fuzzy-optimization method is discussed, and in Section 4, system simulation results are shown. Finally, some conclusion are presented in Section 5.

\section{BEHAVIOR OF THE DFIG BEFORE AND AFTER GRID FAULTS}

Fig. 1 gives the DFIG wind turbine topological structure of the crowbar protection circuit. In this structure, a three-phase non-controlled rectifier bridge is paralleled on the rotor side, and the DC side of the rectifier bridge is connected with the crowbar resistance. When the units work normally, the rotor voltage is rectified on the crowbar, and it maintains a fixed DC voltage level at both ends of the crowbar resistance. When the grid voltage sags and the rotor current increases to the protection threshold, the crowbar circuit operates. At the same time, the rotor side converter is locked to provide an unloading path for the rotor-side fault current for the purpose of converter protection. The following sections analyze the performance of the DFIG before and after grid faults.

\section{A. Mathematical Model of the DFIG before Grid Faults}

The stator and rotor voltages and fluxes in a synchronously rotating reference frame are given in [11], where the rotor variables and parameters are referred to the stator.

$$
\begin{gathered}
\left\{\begin{array}{l}
\boldsymbol{u}_{\mathrm{s}}=R_{\mathrm{s}} \boldsymbol{i}_{\mathrm{s}}+\frac{\mathrm{d} \boldsymbol{\psi}_{\mathrm{s}}}{\mathrm{d} t}+\mathrm{j} \omega_{\mathrm{s}} \boldsymbol{\psi}_{\mathrm{s}} \\
\boldsymbol{u}_{\mathrm{r}}=R_{\mathrm{r}} \boldsymbol{i}_{\mathrm{r}}+\frac{\mathrm{d} \boldsymbol{\psi}_{\mathrm{r}}}{\mathrm{d} t}+\mathrm{j}\left(\omega_{\mathrm{s}}-\omega_{\mathrm{r}}\right) \boldsymbol{\psi}_{\mathrm{r}}
\end{array}\right. \\
\left\{\begin{array}{l}
\boldsymbol{\psi}_{\mathrm{s}}=L_{\mathrm{s}} \boldsymbol{i}_{\mathrm{s}}+L_{\mathrm{m}} \boldsymbol{i}_{\mathrm{r}} \\
\boldsymbol{\psi}_{\mathrm{r}}=L_{\mathrm{m}} \boldsymbol{i}_{\mathrm{s}}+L_{\mathrm{r}} \boldsymbol{i}_{\mathrm{r}}
\end{array}\right.
\end{gathered}
$$

In these equations, all of the parameters are reduced to the stator side, where $\boldsymbol{u}_{\mathrm{s}}=\left[\begin{array}{ll}\boldsymbol{u}_{\mathrm{sd}} & \boldsymbol{u}_{\mathrm{sq}}\end{array}\right]^{\mathrm{T}}$ and $\boldsymbol{u}_{\mathrm{r}}=\left[\begin{array}{ll}\boldsymbol{u}_{\mathrm{rd}} & \boldsymbol{u}_{\mathrm{rq}}\end{array}\right]^{\mathrm{T}}$ are the stator and rotor voltage vectors, $\boldsymbol{i}_{\mathrm{s}}=\left[\boldsymbol{i}_{\mathrm{sd}} \boldsymbol{i}_{\mathrm{sq}}\right]^{\mathrm{T}}$ and $\boldsymbol{i}_{\mathrm{r}}=\left[\boldsymbol{i}_{\mathrm{rd}} \boldsymbol{i}_{\mathrm{rq}}\right]^{\mathrm{T}}$ are the stator and rotor current vectors, $\psi_{\mathrm{s}}=\left[\begin{array}{lll}\psi_{\mathrm{sd}} & \psi_{\mathrm{sq}}\end{array}\right]^{\mathrm{T}}$ and $\boldsymbol{\psi}_{\mathrm{r}}$ 


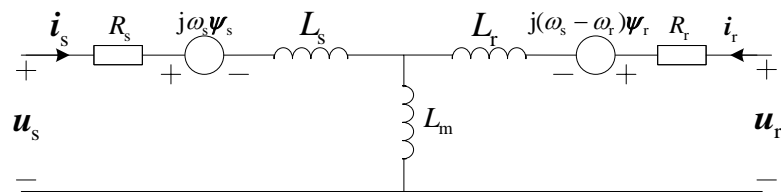

Fig. 2. Equivalent circuit of induction machine for transient analysis.

$=\left[\begin{array}{ll}\psi_{\mathrm{rd}} & \psi_{\mathrm{rq}}\end{array}\right]^{\mathrm{T}}$ are the stator and rotor flux vectors, while $L_{\mathrm{s}}$ and $L_{\mathrm{r}}$ are the stator and rotor self-inductances, respectively. $L_{\mathrm{m}}$ is the mutual inductance, $\omega_{\mathrm{s}}$ is the stator frequency, and $\omega_{\mathrm{r}}$ is the rotor slip frequency. In addtion, $R_{\mathrm{s}}$ and $R_{\mathrm{r}}$ are the stator and rotor resistances.

Based on these equations, the equivalent circuit of the DFIG is shown in Fig. 2. It can be used for transient analysis of an induction machine.

Before the occurrence of a voltage dip, at $t=t_{0}$, the stator voltage space vector is a vector with a constant amplitude $u_{0}$ that rotates at the synchronous electrical angular frequency $\omega_{\mathrm{s}}$. Thus, the stator voltage space vector can be described as:

$$
\boldsymbol{u}_{\mathrm{s}}=u_{0} \mathrm{e}^{\mathrm{j} \omega_{\mathrm{s}} t}
$$

By substituting Equation (2) into (1), the stator voltage orientation is used, per unit $\omega_{\mathrm{s}}=1$, the slip $s=\left(\omega_{\mathrm{s}}-\omega_{\mathrm{r}}\right) / \omega_{\mathrm{s}}$ $=1-\omega_{\mathrm{r}}$, the steady rotor current before a voltage dip is obtained as:

$$
\boldsymbol{i}_{\mathrm{r}\left(0_{-}\right)}=\frac{\frac{L_{\mathrm{s}}}{s} \sqrt{u_{\mathrm{r} d}^{2}+u_{\mathrm{r} q}^{2}} \mathrm{e}^{\mathrm{j} \omega_{b} t}+L_{\mathrm{m}} u_{0}}{\mathrm{j}\left(L_{\mathrm{s}} L_{\mathrm{r}}-L_{\mathrm{m}}^{2}\right)}
$$

where $\omega_{\mathrm{b}}$ is the base angular frequency.

The stator resistance can be neglected in the steady state. Based on (2) and (3), the expressions for the stator flux and rotor flux in the steady state are obtained as:

$$
\left\{\begin{array}{l}
\boldsymbol{\psi}_{\mathrm{s}\left(0_{-}\right)}=\frac{u_{0} \mathrm{e}^{\mathrm{j} \omega_{\mathrm{s}} t}}{\mathrm{j} \omega_{s}} \\
\boldsymbol{\psi}_{\mathrm{r}\left(0_{-}\right)}=\frac{u_{0} \mathrm{e}^{\mathrm{j}(1-s) \omega_{\mathrm{s}} t}}{\mathrm{j} \omega_{\mathrm{s}}}
\end{array}\right.
$$

\section{B. Behavior of the DFIG after Grid Faults}

1) Rotor Current Analysis: The rotor current after a voltage dip consists of two components: the first is a transient attenuation component that is caused by the grid voltage dip, and the second is a steady state current attenuation component.

For the transient attenuation component at time $t=\mathrm{t}_{0}$, a three-phase dip fault is assumed to have occurred at the stator of the DFIG. According to Equation (3), the stator voltage expressions are:

$$
\boldsymbol{u}_{\mathrm{s}}=\left\{\begin{array}{cc}
u_{0} \mathrm{e}^{\mathrm{j} \omega_{\mathrm{s}} t} & t<t_{0} \\
(1-p) u_{0} \mathrm{e}^{\mathrm{j} \omega_{\mathrm{s}} t} & t \geq t_{0}(0 \leq p \leq 1)
\end{array}\right.
$$

where $\mathrm{p}$ is the voltage dip ratio. This implies that the flux in both of the windings does not change. The stator and rotor flux are given by:

$$
\boldsymbol{\psi}_{\mathrm{s}(0)}=\boldsymbol{\psi}_{\mathrm{r}(0)}=p u_{0} /\left(\mathrm{j} \omega_{\mathrm{s}}\right)
$$

This transient flux has an exponential decay. The damping time constant of the dc components in the stator and rotor can be defined as:

$$
\begin{gathered}
T_{s}^{\prime}=\frac{L_{s\left(0_{+}\right)}}{R_{s}} \\
T_{r}^{\prime}=\frac{L_{\mathrm{r}\left(0_{+}\right)}}{R_{r}}
\end{gathered}
$$

In these equations, according to [12], the transient stator inductance can be derived as:

$$
L_{\mathrm{s}\left(0_{+}\right)}=L_{\mathrm{s}}+\frac{L_{\mathrm{r}} L_{\mathrm{m}}}{L_{\mathrm{r}}+L_{\mathrm{m}}}
$$

Similarly, according to [12], the transient rotor inductance can be introduced as:

$$
L_{\mathrm{r}\left(0_{+}\right)}=L_{\mathrm{r}}+\frac{L_{\mathrm{s}} L_{\mathrm{m}}}{L_{\mathrm{s}}+L_{\mathrm{m}}}
$$

In addition, as per [13], the change of the stator and rotor flux after a voltage dip can be expressed mathematically in the rotor reference frame as follows:

$$
\left\{\begin{array}{l}
\psi_{\mathrm{s}\left(0_{+}\right)}=\psi_{\mathrm{s}(0)} \mathrm{e}^{-\frac{t}{T_{\mathrm{s}}^{\prime}}}=\frac{p u_{0} \mathrm{e}^{-\mathrm{j}(1-s) \omega_{\mathrm{s}} t}}{\mathrm{j} \omega_{s}} \mathrm{e}^{-\frac{t}{T_{s}^{\prime}}} \\
\psi_{\mathrm{r}\left(0_{+}\right)}=\psi_{\mathrm{r}(0)} \mathrm{e}^{-\frac{t}{T_{r}^{\prime}}}=\frac{p u_{0}}{\mathrm{j} \omega_{s}} \mathrm{e}^{-\frac{t}{T_{r}^{\prime}}}
\end{array}\right.
$$

Since a detailed analysis of the transient rotor current, $\boldsymbol{i}_{\mathrm{r}\left(0_{+}\right)}^{1}, \mathbf{i}_{\mathrm{r}\left(0_{+}\right)}^{2}$ induced by the transient flux $\boldsymbol{\psi}_{\mathrm{s}\left(0_{+}\right)}, \boldsymbol{\psi}_{r\left(0_{+}\right)}$can be found in [14] it will not be described in this paper. Only the resulting dynamic current expression is given as follows:

$$
\left\{\begin{array}{l}
\boldsymbol{i}_{\mathrm{r}\left(0_{+}\right)}^{1}=-\frac{\psi_{\mathrm{s}\left(0_{+}\right)} L_{\mathrm{m}}}{L_{\mathrm{s}\left(0_{+}\right)}\left(L_{\mathrm{r}}+L_{\mathrm{m}}\right)} \\
\boldsymbol{i}_{\mathrm{r}\left(0_{+}\right)}^{2}=\psi_{\mathrm{r}\left(0_{+}\right)} / L_{\mathrm{r}\left(0_{+}\right)}
\end{array}\right.
$$

By substituting Equation (12) into (13), the general transient rotor current is given by:

$$
\boldsymbol{i}_{\mathrm{r}\left(0_{+}\right)}=\boldsymbol{i}_{\mathrm{r}\left(0_{+}\right)}^{1}+\mathbf{i}_{\mathrm{r}\left(0_{+}\right)}^{2}=\frac{p u_{0}}{\mathrm{j} \omega_{\mathrm{s}}}\left(\frac{\mathrm{e}^{-\frac{t}{T_{r}^{\prime}}}}{L_{\mathrm{r}\left(0_{+}\right)}}-\frac{L_{\mathrm{m}} \mathrm{e}^{-\mathrm{j}(1-s) \omega_{\mathrm{s}} t} \mathrm{e}^{-\frac{t}{T_{s}^{\prime}}}}{L_{\mathrm{r}} L_{\mathrm{s}\left(0_{+}\right)}}\right)
$$

For the steady state current attenuation component $\boldsymbol{i}_{\mathrm{r}\left(0_{++}\right)}$, based on (4), the term can be written as:

$$
\mathbf{i}_{\mathrm{r}\left(0_{++}\right)}=\boldsymbol{i}_{\mathrm{r}\left(0_{-}\right)} \mathrm{e}^{-\frac{t}{T_{r}^{\prime}}}
$$

Thus, by adding Equations (14) and (15), the final expression of the rotor currents during a voltage dip can be written as follows: 


$$
\begin{aligned}
& \boldsymbol{i}_{\mathrm{r}\left(0_{+}\right) \text {sum }}=\boldsymbol{i}_{\mathrm{r}\left(0_{+}\right)}+\boldsymbol{i}_{\mathrm{r}\left(0_{+}\right)}=\frac{p u_{0}}{\mathrm{j} \omega_{\mathrm{s}}}\left(\frac{\mathrm{e}^{-\frac{t}{T_{r}^{\prime}}}}{L_{\mathrm{r}\left(0_{+}\right)}}-\frac{L_{\mathrm{m}} \mathrm{e}^{-\mathrm{j}(1-s) \omega_{\mathrm{s}} t} \mathrm{e}^{-\frac{t}{T_{\mathrm{s}}^{\prime}}}}{L_{\mathrm{r}} L_{\mathrm{s}\left(0_{+}\right)}}\right)+ \\
& \frac{\frac{L_{\mathrm{s}}}{s} \sqrt{u_{\mathrm{r} d}^{2}+u_{\mathrm{r} q}^{2}} \mathrm{e}^{\mathrm{j} \omega_{\mathrm{b}} t}+L_{\mathrm{m}} u_{0}}{\mathrm{j}\left(L_{\mathrm{s}} L_{\mathrm{r}}-L_{\mathrm{m}}^{2}\right)} \mathrm{e}^{-\frac{t}{T_{r}^{\prime}}}
\end{aligned}
$$

2) Analysis of the DFIG Absorbing Reactive Power: When a voltage dip has occurred and the rotor overcurrent is large enough to trigger the crowbar protection, the DFIG may lose its controllability and behaves as a squirrel-cag induction machine. The impedance equivalent circuit is shown in Fig. 3 where $R_{\mathrm{cb}}$ is the crowbar reactance.

Based on Fig. 3, the equivalent impedance of the DFIG with the crowbar can be described as:

$$
Z=R+j X=\left(R_{s}+j X_{s}\right)+j X_{m} / /\left(j X_{r}+R_{\mathrm{r}}+\frac{R_{c b}}{s}\right)
$$

where:

$$
\begin{gathered}
R=R_{s}+\frac{\left(R_{\mathrm{r}}+\frac{R_{c b}}{s}\right) X_{m}^{2}}{\left(R_{\mathrm{r}}+\frac{R_{c b}}{s}\right)^{2}+\left(X_{m}+X_{r}\right)^{2}} \\
X=X_{s}+\frac{X_{m}\left[\left(R_{\mathrm{r}}+\frac{R_{c b}}{s}\right)^{2}+X_{r}\left(X_{m}+X_{r}\right)\right]}{\left(R_{\mathrm{r}}+\frac{R_{c b}}{s}\right)^{2}+\left(X_{m}+X_{r}\right)^{2}}
\end{gathered}
$$

If the influence of the transient current for the steady state power of the DFIG is ignored, based on the relationship between the active power and reactive power, it is possible to write:

$$
S=P+j Q=\frac{3}{2} \dot{U}_{s} \dot{I}_{s}^{*}=\frac{3}{2} U_{s}^{2}\left(\frac{R+j X}{R^{2}+X^{2}}\right)
$$

The reactive power that the DFIG absorbs from the grid during a fault can be obtained as:

$$
Q_{R}=\frac{3}{2} U_{s}^{2} \frac{X}{R^{2}+X^{2}}
$$

From Eq. (21), it can be seen that the reactive power is determined by the stator voltage, the value of the crowbar resistance, and the rotor speed of the DFIG. This absorbed reactive power will lead to a further voltage drop in the grid. Therefore, the absorbed reactive power should be as little as possible.

\section{MULTI-OBJECTIVE FUZZY OPTIMIZATION STRATEGY OF CROWBAR RESISTANCES}

The crowbar protection of the LVRT in a doubly fed wind power generator should have the following optimization goals. First, it should achieve the safest generator operation performance. Second, it should possess the fastest fault recovery. Based on the squirrel-cage induction machine

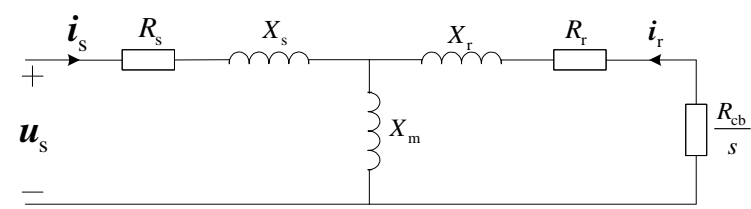

Fig. 3. Impedance equivalent circuit of the DFIG with crowbar.

operating characteristic of the DFIG after the crowbar is applied, the optimization objective function is established to achieve the lowest rotor overcurrent after voltage dips, and the lowest amount of reactive power absorbed from the grid. In order to do that, the optimization objective function of the crowbar resistance can be constructed as follows.

\section{A. Objective Functions}

1) Rotor Current Objective Function $\left(F_{C}\right)$ : On the one hand, according to Equation (16), although the current vector does not reach the maximum value exactly at $t=T / 2$, the current after half a period gives a good approximation of the maximum current [15]. On the other hand, after the crowbar is in operation, the rotor current damping time constant $T_{r}^{\prime}$ becomes $T_{r c b}^{\prime}$

$$
T_{r c b}^{\prime}=\frac{L_{\mathrm{r}\left(0_{+}\right)}^{\prime}}{R_{r}+R_{c b}}
$$

Thus, the maximum rotor current $I_{\mathrm{rmax}}$ after the grid voltage dip can be obtained by substituting $T_{r c b}^{\prime}=\frac{L_{\mathrm{r}\left(0_{+}\right)}}{R_{r}+R_{c b}}, t=\frac{T}{2}$, and $\mathrm{p}=1$ in (16) for:

$$
F_{C}=I_{\mathrm{rmax}}=\left|\boldsymbol{i}_{\mathrm{r}\left(0_{+}\right) \operatorname{sum}}\right|_{t=\frac{T}{2}, T_{r}=T_{r c b}^{\prime}}
$$

\section{2) Absorbed Reactive Power Objective Function $\left(F_{R}\right)$ :}

According to Equation (21), when the crowbar is in operation, the objective function of the reactive power that the DFIG absorbs from the grid can be expressed as follows:

$$
F_{R}=\frac{3}{2} U_{s}^{2} \frac{X}{R^{2}+X^{2}}
$$

\section{B. Problem Constraints}

The constraints are:

1) Rotor Overcurrent: As shown by Eqn. (23), the value of the crowbar resistance must be large enough to limit the DFIG rotor overcurrent and to make the time constant attenuate quickly. According to Equation (22), if $T_{r c b \max }^{\prime}$ is defined as the maximum damping time constant, the value of the crowbar resistance can be described as:

$$
g_{1}\left(R_{c b}\right)=R_{c b}>\frac{L_{\mathrm{r}\left(0_{+}\right)}^{\prime}}{T_{r c b \max }^{\prime}}-R_{r}
$$

2) Rotor Overvoltage: If $U_{\text {rmax }}$ is defined as the maximum rotor overvoltage during voltage sag faults, it is a function related to $R_{\mathrm{cb}}$. 


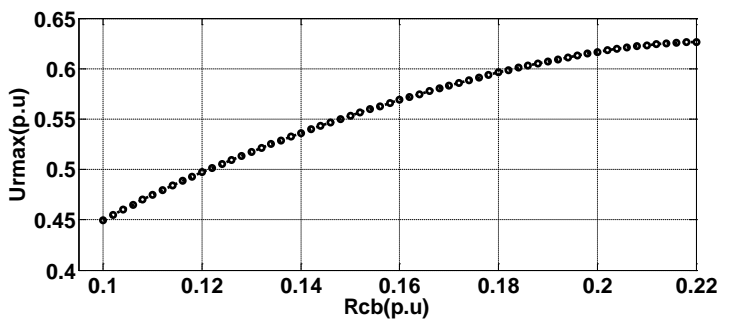

Fig. 4. Relationship curve between the maximum rotor voltage and crowbar resistances.

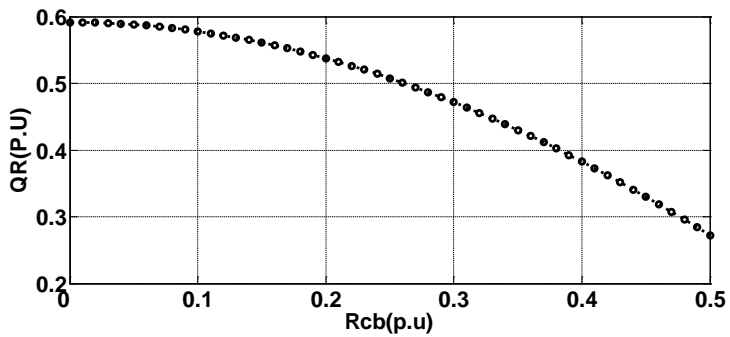

Fig. 5. Relationship curve between the absorbed reactive power and crowbar resistances.

$$
U_{\text {rmax }}=I_{\text {rmax }} R_{c b}
$$

Thus, the maximum rotor overvoltage monotonically increases with an increase of the crowbar reactance after the crowbar is in operation. For example, for a 2 MW DFIG, Fig. 4 shows the relationship between $U_{\text {rmax }}$ and $R_{\mathrm{cb}}$.

In practical applications, in order to prevent the rotor overvoltage from reaching values beyond the safety limit of the rotor voltage, and to avoid damage to both the rotor side converter and the dc-capacitor, a safety margin coefficient $\lambda$ is adopted, to which the upper limit of the crowbar reactance value is connected as follows:

$$
g_{2}\left(R_{c b}\right)=R_{c b}=\frac{U_{\mathrm{r} \max }}{I_{\mathrm{r} \max }}<\lambda \frac{U_{\mathrm{r} \lim }}{I_{\mathrm{r} \max }}
$$

where $U_{\text {rlim }}$ is the rotor voltage limit.

3) DFIG Absorbing Reactive Power: According to Equation (24), for example, for a 2 MW DFIG Fig. 5 shows the relationship between $F_{\mathrm{R}}$ and $R_{\mathrm{cb}}$. As can be seen, with the increase of $R_{\mathrm{cb}}$, the reactive power $\mathrm{Q}_{\mathrm{R}}$ that DFIG absorbs from the grid gradually decreases.

During the LVRT process of an actual wind power plant, the reactive power absorbed by the DFIG should be as little as possible to benefit the quick recovery of the dropped grid voltage. Assuming that $\mathrm{Q}_{\mathrm{s}}$ is the reactive power which the DFIG should provide to the grid when the crowbar is in operation, according to the LVRT test requirements of national wind turbine generators, if the reactive power that the DFIG absorbs from the grid is less than $\beta$ times $\mathrm{Q}_{\mathrm{s}}$, then the objective function of the reactive power will meet the following constraint conditions:

$$
g_{3}\left(R_{c b}\right)=\frac{3}{2} U_{s}^{2} \frac{X}{R^{2}+X^{2}} \leq \beta Q_{s}
$$

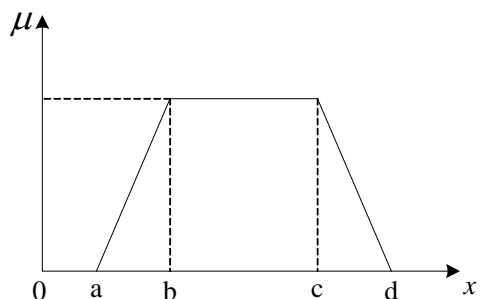

Fig. 6. Membership function distribution of constraint conditions.

\section{Fuzzy Processing of Multi-Objective Optimization Model}

During actual engineering design, many parameters are not the determined values. There is a transition interval between the absolute allowable values and the absolute non-allowable values of parameters. This produces the so-called fuzziness. However, the problem regarding the transition interval is not taken into account in common optimization design methods. In turn, the optimal optimization effect cannot be achieved in most cases. In this paper, considering the fuzzy factors of the crowbar resistance parameters involved in the LVRT, the fuzzy set theory is introduced into the design so that the optimization results are much more suitable for actual engineering applications. The fuzzy set theory generalizes the classical set theory to allow for partial membership with a smooth boundary. The degree of membership in a set is expressed by a number between 0 and 1 , where 0 means entirely not in the set, 1 means completely in the set, and a number in between 0 and 1 means partially in the set [16]. The details of the fuzzy optimization algorithm are described below.

1) Fuzzy Processing of Constraint Conditions: The fuzzy processing of constraint conditions is performed to establish the membership functions for each allowable fuzzy interval. The distribution of the linear membership function is shown in Fig. 6.

From Fig. 6, the constraint condition membership function can be written as follows [17]:

$$
\begin{aligned}
& \mu_{G 1}(x)= \begin{cases}0 & x<a \\
\frac{x-a}{b-a} & a \leq x \leq b \\
1 & b \leq x<c\end{cases} \\
& \mu_{G 2}(x)= \begin{cases}1 & b \leq x<c \\
\frac{d-x}{d-c} & c \leq x<d \\
0 & x \geq d\end{cases}
\end{aligned}
$$

The upper and lower limits of the constraint conditions are determined by the method of the amplification coefficient, that is $a=\varepsilon b, d=\delta c$. In general the coefficient of the upper limit is $\varepsilon=1.05 \sim 1.30$, and the coefficient of the lower limit is $\delta=0.75 \sim 0.90$. The membership function of 


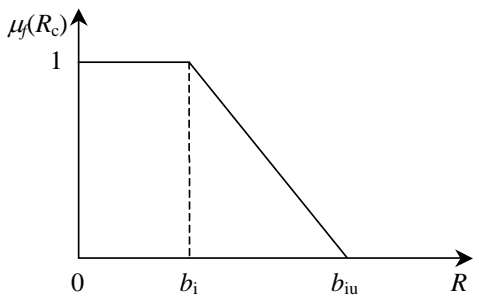

Fig. 7. Membership function with negative slope.

the fuzzy constraint with the loosest constraint conditions can be obtained by processing the constraint conditions as membership functions.

In this section, the constraint conditions of the crowbar resistance values in Eqs. (25), (27), and (28) show fuzziness and need for fuzzing. A membership function with a negative slope is shown in Fig. 7 and is adopted as the fuzzy constraint set of the crowbar resistance value. When $\lambda$ and $\beta$ are less than 1 , that is a converter without overcurrent and overvoltage and where the reactive power the DFIG absorbed from the grid is less than the one, which the DFIG should provide to the grid when the crowbar is in operation. In these conditions, the satisfaction of the crowbar resistance value is equal to 1 . Otherwise, when $\lambda$ and $\beta$ are larger than 1 , and are gradually increased within the specified safety margin, the satisfaction of the crowbar resistance value is dropped down from 1 to 0 .

2)Fuzzy Processing of the Objective Functions:

Step 1: Construct a fuzzy objective function for every sub-objective function.

During the fuzzy processing of the objective function, the extremum method is often employed to construct the fuzzy object set. Equations (23) and (24) are the objective functions of the crowbar resistance value when a grid fault takes place. These are then transferred into the fuzzy objective functions within the closed interval $[0,1]$. The upper limit $F_{i}^{\max }$ and the lower limit $F_{i}^{\text {min }}$ of each constraint condition are estimated according to Equations (25), (27), and (28), as well as the coefficients of the safety margin $\lambda$ and $\beta$. Finally, in accordance with [18], the fuzzy objective function for every sub-objective function $F_{i}$ (ith objective function $F_{i}$ ) is:

$$
F_{i}\left(R_{\mathrm{c}}\right)=\frac{F_{i}^{\max }-F_{i}}{F_{i}^{\max }-F_{i}^{\min }}
$$

Step 2: Construct a membership function for every sub-objective function fuzzy objective set.

The ith objective function $F_{i}$ is constructed by a membership function $\mu_{i}$ defined by [19].

$$
\mu_{i}\left(F_{i}\right)= \begin{cases}1 & F_{i} \leq F_{i}^{\min } \\ \frac{F_{i}^{\max }-F_{i}}{F_{i}^{\max }-F_{i}^{\min }} & F_{i}^{\min }<F_{i}<F_{i}^{\max } \\ 0 & F_{i} \geq F_{i}^{\max }\end{cases}
$$

\section{Step 3: Fuzzy conditional extremum estimation}

According to the level set method of the fuzzy optimization theory, a variable $\gamma$ is used to separate the fuzzy sub-set into several ordinary sets $F_{\gamma}$. Then, the extremum of the objective function in $F_{\gamma}$ is obtained. Finally, the extremum of the fuzzy condition in $F_{\gamma}$ can be derived as:

$$
F_{\gamma}(x)=\left\{x \mid \mu_{i}\left(F_{i}\right) \geq \gamma\right\}, \gamma \in[0,1]
$$

where $\mathrm{x}$ is an optimized design variable.

3) Multi-Objective Fuzzy Optimization Mathematical Model: Based on the above processing, the multi-objective optimized mathematical model described in this paper is applied to solve a single-objective fuzzy optimization problem. The mathematical description of this problem is as follows:

$$
\begin{aligned}
& \text { Solve } X=\left[x_{1}, x_{2}, \ldots x_{n}, \gamma\right]^{T} \\
& \max \gamma \\
& \text { s.t. }\left\{\begin{array}{l}
\mu_{i}\left(F_{i}\right) \geq \gamma, i=1,2, \cdots m \\
\mu_{i}\left(g_{i}\right) \geq \gamma, j=1,2, \cdots n
\end{array}\right.
\end{aligned}
$$

where $\mu_{i}\left(F_{i}\right)$ and $\mu_{i}\left(g_{i}\right)$ are the objective function and the membership function of the constraint conditions after the fuzzy processing.

4) Genetic Algorithm Implementation: The optimum solution of the fuzzy optimization problem as described in Equation (34) can be calculated by an ordinary optimization algorithm. However, this optimization method usually falls into a local optimization, preventing it from achieving a globally optimal solution. Since genetic algorithms have the advantages of a strong global search and of a high convergence rate, they are employed to solve the multi-objective fuzzy optimization model in this paper.

The use of genetic algorithms (GA), which are a class of evolutionary algorithms (EA), has become prominent in recent years [20]. First introduced in Holland in 1975, the GA is a model in which an initial population develops into a new generation, through procreation, mutation, and crossover processes among all the members. A GA offers several advantages over traditional optimization algorithms [21]-[23].

1. A GA operates only with the coding chromosomes, which are optimized in accordance with objective functions and proper constraints. Therefore, the need for initial system information to begin the optimization process is eliminated.

2. Another advantage of a GA, and notably one of its essential distinctions from traditional optimization algorithms, is its ability to explore numerous regions of the search space, by iteratively analyzing multiple points of a population.

3. Finally, in a GA only the best candidates among the members are chosen, leading to global minimum 


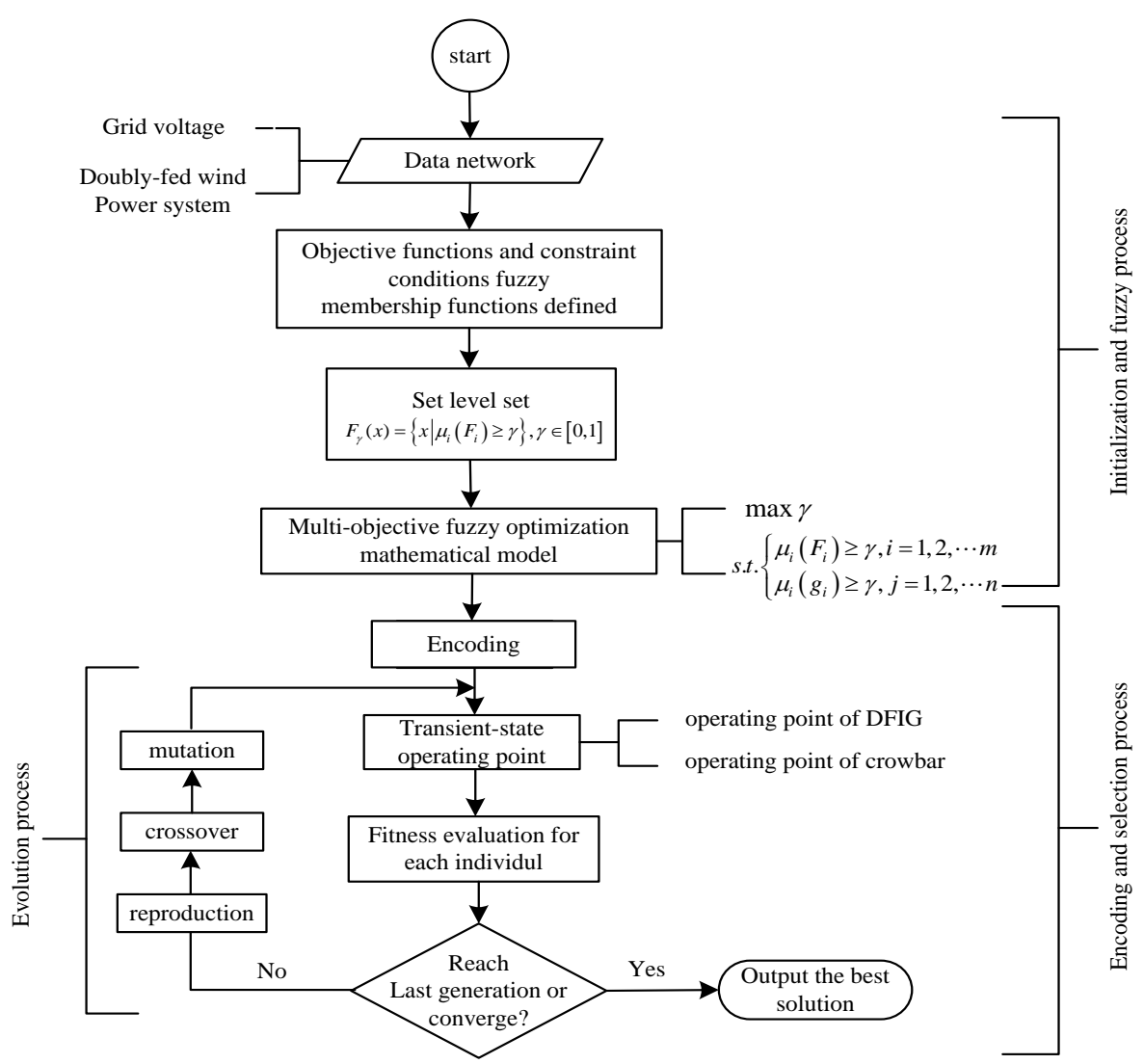

Fig. 8. Multi-objective fuzzy genetic algorithm process.

convergence.

When solving the crowbar resistances fuzzy optimization problem using a GA, the following steps should be followed:

Step 1: Encoding

The application of the GA begins with parameter encoding. Each individual in the population is a candidate solution, the components of which comprise all the decision variables in the system. The decision variables in the case of the crowbar resistance fuzzy optimization include the stator voltage $u_{0}$, the voltage dip ratio $p$, and the crowbar resistance value $R_{\mathrm{cb}}$. The solution variables are expressed as floating point numbers and integers. This representation is more efficient than binary coding, because it does not require converting the resulting variables into the binary type. Moreover, less computer memory is needed to store the population.

Step 2: Evaluation

Each individual in the population is given a goodness value according to the Fitness Function (FF). This value is used to drive the evolution process. At the same time, each chromosome is assigned a fitness value, which determines both the individual's capacity to adapt to the environment, and its estimated survival probability in the subsequent generation.

\section{Step 3: Selection}

Those individuals with the highest fitness values are selected as potential parents, since they are more likely to survive. Consequently, the larger the chromosome's fitness, the greater the probability of survival in the next generation. Therefore, a roulette wheel selection is adopted to select the most suitable individuals to be reproduced.

\section{Step 4: Crossover}

A one-point crossover operation is used, in which one crossover point is required to create new offspring chromosomes. This is arbitrarily chosen after the random selection of two chromosome parents.

\section{Step 5: Mutation}

The mutation operator's final objective is to add diversity to the population. Therefore, the operator arbitrarily selects individuals and changes some of their characteristics. The mutation is achieved with a small probability after crossover, and it creates new individuals with information not included in previous generations.

According to the description given in section 3, the complete multi-objective fuzzy optimization process of the crowbar resistance value is shown in Fig. 8.

\section{SIMULATION RESULTS}

\section{A. Crowbar Resistance Fuzzy Optimization Design}

The proposed multi-objective fuzzy optimization genetic algorithm has been applied to solve the crowbar resistances optimization problem for the DFIG LVRT. The optimization 


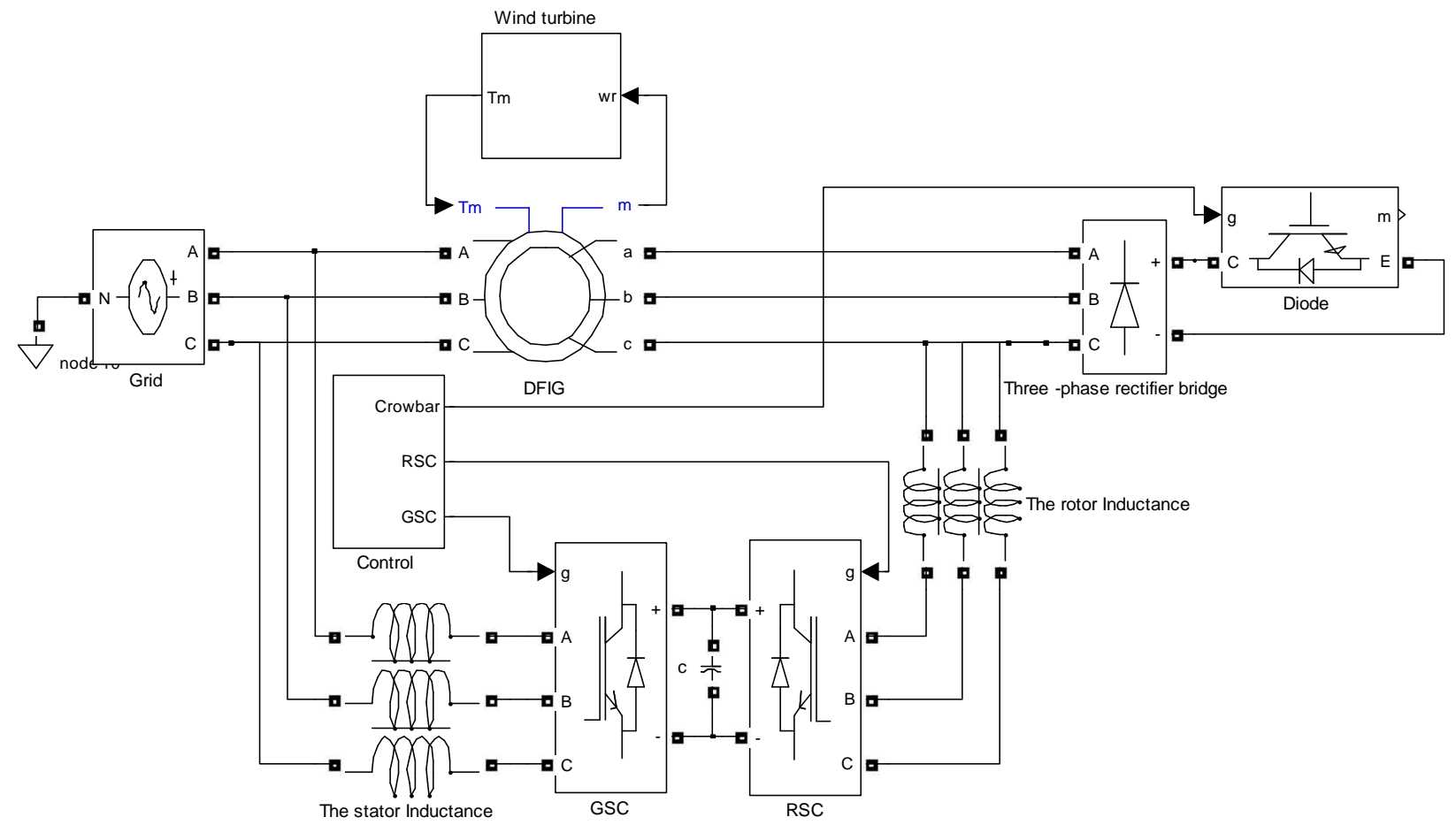

Fig. 9. Simulation model of the system.

TABLE I

Single objective OPtimal SOlUtion Nominal Parameters

\begin{tabular}{ccc}
\hline Objective function & Optimal solution $R_{\mathrm{cb}}$ (p.u) & Maximum value(p.u) \\
\hline Single objective function $F_{\mathrm{C}}$ & 0.037 & 1.15 \\
Single objective function $F_{\mathrm{R}}$ & 0.048 & 0.35 \\
\hline
\end{tabular}

algorithm has been conducted on a 3 MW DFIG. The parameters of the generators are given in the Appendix. The DFIG experiences a voltage sag of $80 \%$ at the grid and it is sustained for a period of $625 \mathrm{~ms}$.

According to Section 2.2, the transient stator and rotor inductances are:

$$
\begin{gathered}
L_{\mathrm{s}\left(0_{+}\right)}=L_{\mathrm{s}}+\frac{L_{\mathrm{r}} L_{\mathrm{m}}}{L_{\mathrm{r}}+L_{\mathrm{m}}}=0.232 \mathrm{pu}, \\
L_{\mathrm{r}\left(0_{+}\right)}=L_{\mathrm{r}}+\frac{L_{\mathrm{s}} L_{\mathrm{m}}}{L_{\mathrm{s}}+L_{\mathrm{m}}}=0.238 \mathrm{pu}
\end{gathered}
$$

The maximum rotor current, calculated from Equation (23), is 5.2 p.u. The value of the crowbar resistance is chosen so that the rotor voltage limit $U_{\text {r-limit }}$ is 1.5 p.u, the stator and rotor current limit $\mathrm{I}_{\mathrm{r}-\mathrm{limit}}$ is $1.5 \mathrm{p}$.u, and the reactive power absorbed by the DFIG from the grid is 0.5 p.u.

The best result of the GA was obtained with the following algorithm parameters:

Number of generations: 100; population size: 55; crossover probability: 0.85 ; mutation probability: 0.01 .

After 100 generations it was found that all of the individuals had reached almost the same fitness value. This shows that GA has reached the optimal solution. Table I lists the optimal solutions of the crowbar resistance and the individual objective function values corresponding to each solution. The algorithm took $126 \mathrm{~s}$ to reach the optimal solution. The crowbar resistance design effect of both the common method and the multi-objective fuzzy genetic algorithm are compared. This comparison is given in Table II. It is obvious that the multi-objective fuzzy genetic algorithm obtained the best compromise effect.

\section{B. The Optimization Results Validation}

The optimized value of the crowbar resistance in the above is applied to a crowbar circuit under the conditions of DFIG grid faults. The transient performances are compared with the crowbar resistance which is designed by the common method. The common method selects a value of the crowbar resistance according to reference [15], the crowbar resistance is selected based on the permissible value of the rotor overvoltage. A $3 \mathrm{MW}$ DFIG connected to a power system network was simulated using MATLAB/SIMULINK software. The simulation model is shown in Fig. 9. The DFIG parameters are given in the Appendix. The behavior of the DFIG during a voltage sag of $80 \%$ at the generator bus for $625 \mathrm{~ms}$ is simulated at $\mathrm{t}=4 \mathrm{~s}$. At the moment of the voltage dip the generator speed is $0.8 \mathrm{p} . \mathrm{u}$, the wind speed is $12 \mathrm{~m} / \mathrm{s}$, and the generator is operated at a unity power factor. When the grid voltage sags because the rotor overcurrent crowbar 
TABLE II

COMMON DESIGN AND MULTI-OBJECTIVE GENETIC FUZZY ALGORITHM COMPARED

\begin{tabular}{|c|c|c|c|c|}
\hline Algorithm & $R_{\mathrm{cb}}$ solution(p.u) & $\mathrm{I}_{\mathrm{rmax}}(\mathrm{p} . \mathrm{u})$ & $\mathrm{Q}_{\text {rmax }}(\mathrm{p} . \mathrm{u})$ & $\mathrm{U}_{\text {rmax }}(\mathrm{p} . \mathrm{u})$ \\
\hline Common method & 0.038 & 1.1 & 0.64 & 0.92 \\
\hline Multi-objective fuzzy genetic algorithm & 0.045 & 0.7 & 0.39 & 1.08 \\
\hline
\end{tabular}

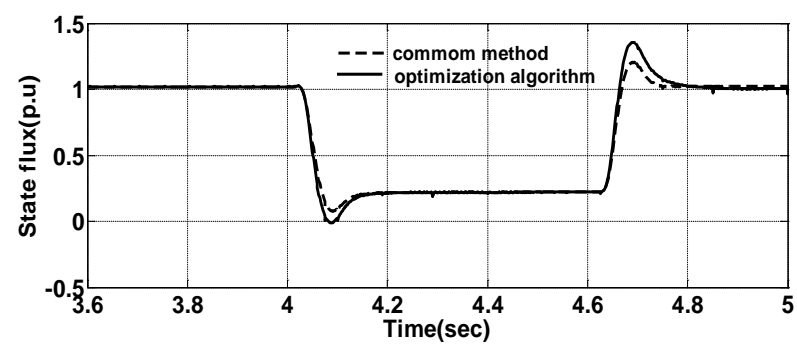

Fig. 10. Stator flux.

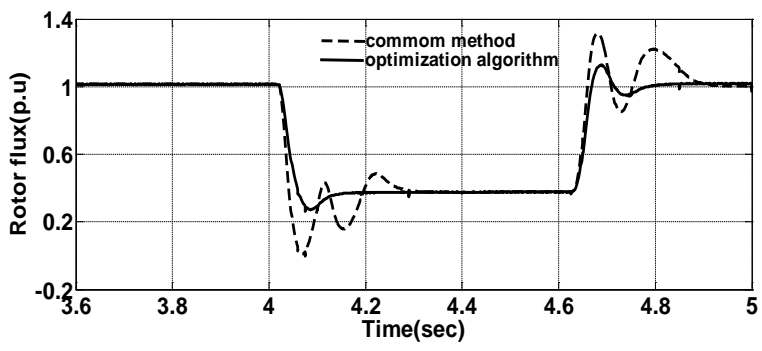

Fig. 11. Rotor flux.

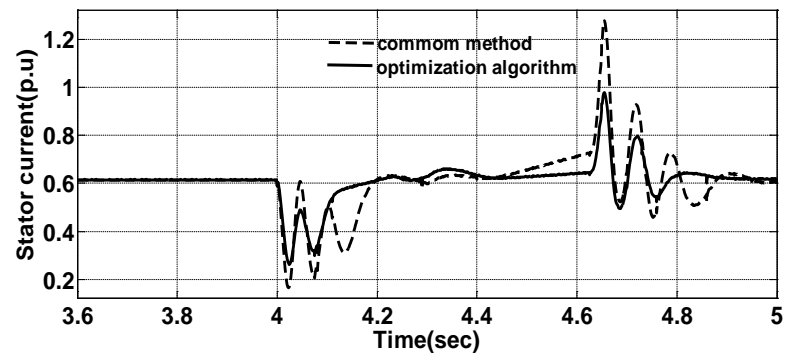

Fig. 12. Stator current.

protection is in operation, the crowbar action lasts for around $70 \mathrm{~ms}$. After the crowbar is cut off, the rotor converter is immediately restarted and provides reactive support to the grid. To prevent converter overcurrent, after the rotor side converter restarts, no active power is generated.

The stator flux during the voltage sag is shown in Fig. 10. The stator flux has the same change trend for the crowbar resistance regardless of whether it was designed by the common method or by the optimization method. However, for the optimization method, at the beginning and end of the voltage sag the transient peak is slightly increased. This is due to the fact that when the rotor current is not equal to zero, the dynamic response of the stator flux is affected by the flux coupling between the stator and the rotor. The smaller the value of the crowbar resistance, the better of the stator flux attenuation. The rotor flux during the voltage sag is shown in Fig. 11. When compared with the common design method, the optimization method that designed the crowbar resistance

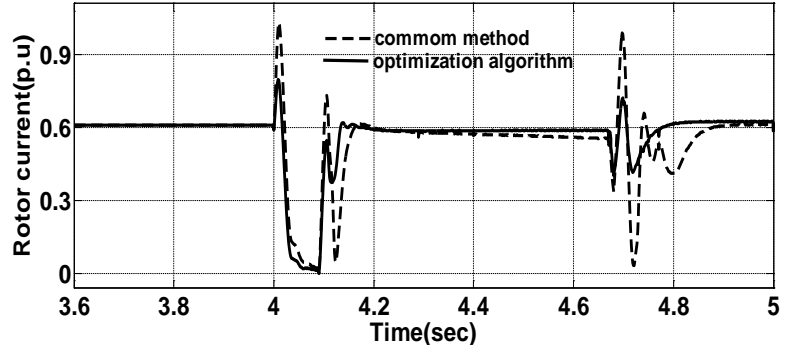

Fig. 13. Rotor current.

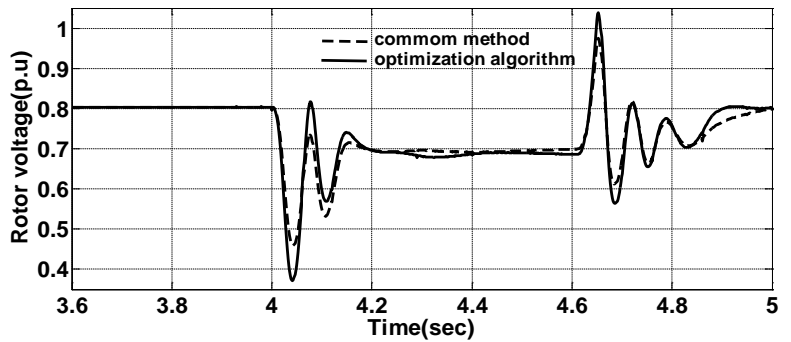

Fig. 14. Rotor voltage.

can make the rotor flux at the beginning of the voltage sag have a smaller peak and it can make the end of the voltage sag have a faster recovery speed. The rotor flux oscillations are attenuated. The reason for this is that from Equation (23), after the crowbar is in operation, the rotor current damping time constant is increased, which accelerates the attenuation of the rotor flux.

The stator and rotor current responses are shown in Figs. 12 and 13. As can be noticed, if the common design method is employed, the stator and rotor overcurrents reach maximum values of 1.3 and 1.15 p.u. during the fault, respectively. It can also be seen that the stator overcurrents are near the constraint boundary. At the same time, by using the proposed optimization algorithm, the maximum values of stator and rotor overcurrents decrease to 0.95 and 0.75 p.u., respectively. These are far beyond the safety limit of the converter. In addition, the transient time constant is smaller. The rotor voltage response is shown in Fig. 14. The multi-objective fuzzy optimization algorithm obtains the compromise solution of the crowbar resistance. Furthermore, the transient peak is slightly increased. However, it is less than the safety limit of the rotor voltage.

The active and reactive power responses are shown in Figs. 15 and 16. The stator active power due to the occurrence of the voltage sag decreases to nearly zero. Then, after clearing the fault it starts to oscillate until it reaches its steady state value. It is evident that when compared with the common design method, the proposed optimization algorithm has a 


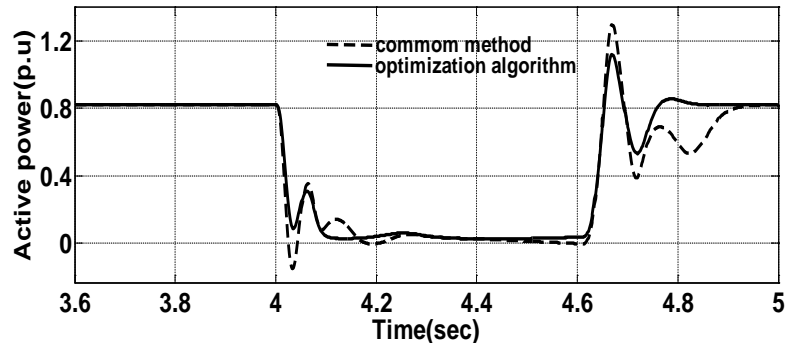

Fig. 15. Active power.

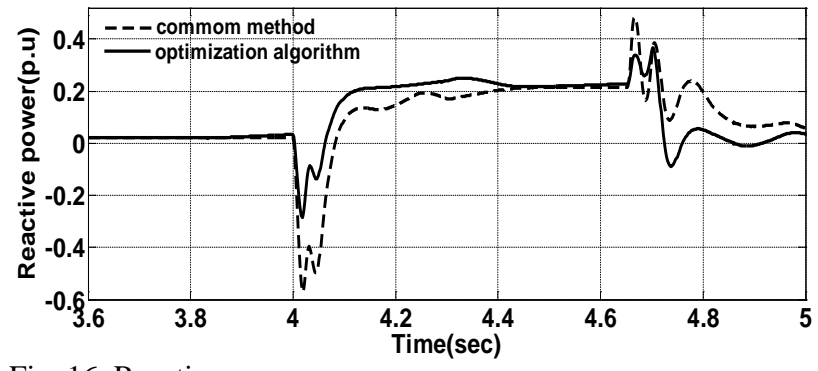

Fig. 16. Reactive power.

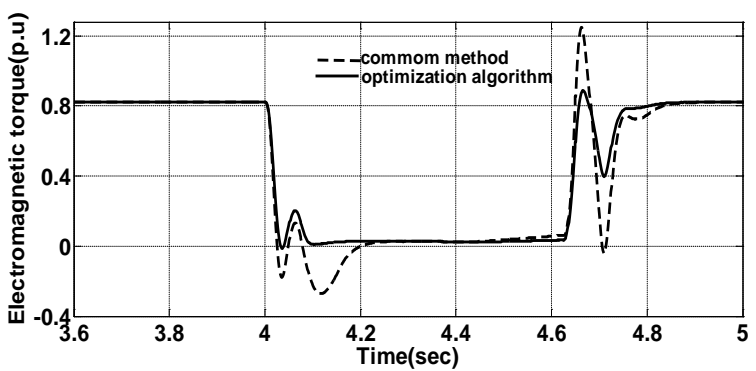

Fig. 17. Electromagnetic torque.

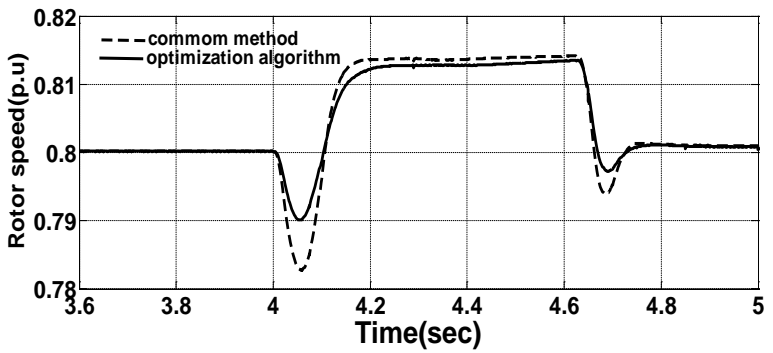

Fig. 18. Rotor speed.

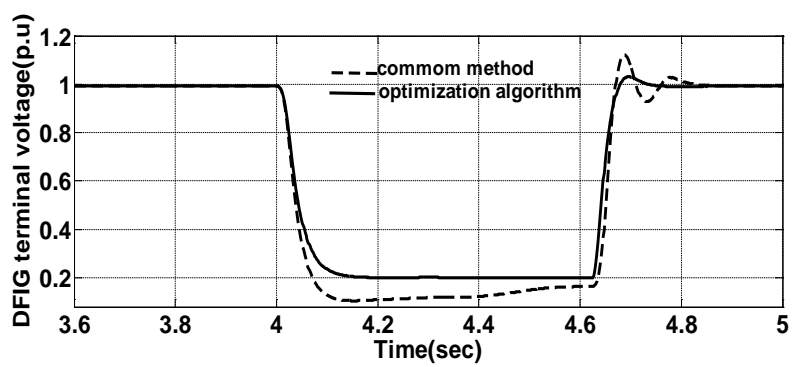

Fig. 19. Grid terminal voltage.

smaller transient peak during the fault. In addition, the optimized value of the crowbar resistance makes the DFIG absorb comparatively less reactive power from the grid. This is a benefit caused by the quick recovery of the dropped terminal voltage. However, for the common design method, the reactive power magnitude is increased to almost 0.6 p.u, which is beyond the design target.

The dynamic behavior of the electromagnetic torque is shown in Fig. 17. It is clear that if the common design method is employed, the electromagnetic torque magnitude is increased to 1.3 p.u. This tends to damage the mechanical parts in practical applications.

The rotor speed is shown in Fig. 18. During the voltage sag the active power decreases and the rotor speed increases. The speed peak is decreased in the optimization design. The recovery process of the DFIG terminal voltage is shown in Fig. 19. If the common design is employed, the terminal voltage experiences a dip below $80 \%$, the recovery voltage transient peak is increased to 1.17 p.u., and the recovery process is unduly delayed (at $\mathrm{t}=4.85 \mathrm{~s}$ ). The proposed optimization algorithm leads to a rapid recovery of the terminal voltage of the DFIG to its nominal voltage, at $\mathrm{t}=$ 4.72s.

\section{CONCLUSION}

This study investigated the multi-objective fuzzy optimization of crowbar resistances for the LVRT of DFIG under voltage dips with a genetic algorithm. To effectively improve the security of the LVRT problem and to provide designers with diverse alternative options, a multi-objective fuzzy optimization model with technical and operational constraints has been constructed to minimize rotor overcurrent and to simultaneously reduce the reactive power that DFIGs absorb from the grid. A genetic algorithm has been successfully applied to the multi-objective fuzzy optimization problem and it derived a satisfactory decision by finding optimal solutions. The proposed algorithm has been applied to a 3 MW DFIG LVRT. A comparison between the results obtained with the crowbar resistance designed by the proposed optimization algorithm and by the common design method proves that the optimized crowbar resistance makes the LVRT have a higher safety performance and a faster recovery speed from grid faults. The multi-objective fuzzy optimization emphasizes non-dominated solutions and simultaneously maintains diversity in the non-dominated solutions. In the future, the proposed approach can be widely applied to solve safety-constrained optimum problems in power systems.

\section{APPENDIX}

PARAMETERS OF THE 3-MW DFIG

$\mathrm{u}_{\text {base }}=960 \mathrm{~V}$ (line-line), $\mathrm{S}_{\text {base }}=3 \mathrm{MVA}, \mathrm{f}_{\text {base }}=50 \mathrm{~Hz}$

$\mathrm{u}_{\mathrm{s}}=0.58 \mathrm{pu}, \mathrm{u}_{\mathrm{r}}=0.23 \mathrm{pu}, \mathrm{L}_{\mathrm{s}}=0.07 \mathrm{pu}, \mathrm{L}_{\mathrm{r}}=0.17 \mathrm{pu}, \mathrm{L}_{\mathrm{m}}=3.3 \mathrm{pu}$,

$\mathrm{R}_{\mathrm{s}}=0.00706 \mathrm{pu}, \mathrm{R}_{\mathrm{r}}=0.005 \mathrm{pu}$ 


\section{ACKNOWLEDGMENT}

This work was supported by National Nature Science Foundation of China (51207002), the Industrial Science and Technology Research of Shaanxi Province(2013K07-12 and 2012K06-46), the Scientific Research Program Funded by Shaanxi Provincial Education Department (2013JK1017), the Technology transfer to promote engineering project of $\mathrm{Xi}$ 'an bureau of science and technology (CXY1347(4)) and the key research project Funded by Baoji University of Arts and Sciences(ZK11068).

\section{REFERENCES}

[1] H. Li, C. Yang, Y. G. Hu, B. Zhao, M. Zhao, and Z. Chen, "Fault-tolerant control for current sensors of doubly fed induction generators based on an improved fault detection method,” Measurement, Vol. 47, No. 2, pp. 929-937, Jan. 2014.

[2] M. Rahimi and M. Parniani, "Grid-fault ride-through analysis and control of wind turbines with doubly fed induction generators," Electric Power Systems Research, Vol. 80, No. 2, pp. 184-195, Feb. 2010.

[3] M. Alberdi, M. Amundarain, A. Garrido, and I. Garrido, "Neural control for voltage dips ride-through of oscillating water column-based wave energy converter equipped with doubly-fed induction generator," Renewable Energy, Vol. 48, pp. 16-26, Dec. 2012.

[4] K. Vinothkumar and M. P. Selvan, "Novel scheme for enhancement of fault ride-through capability of doubly fed induction generator based wind farms," Energy Conversion and Management, Vol. 52, No. 7, pp. 2651-2658, Jul. 2011.

[5] J. Ouyang and X. Xiong, "Research on short-circuit current of doubly fed induction generator under non-deep voltage drop,” Electric Power Systems Research, Vol. 107, pp. 158-166, Feb. 2014.

[6] J. Mohammadi, S. Afsharnia, and S. Vaez-Zadeh, "Efficient fault-ride-through control strategy of DFIG-based wind turbines during the grid faults," Energy Conversion and Management, Vol. 78, pp. 88-95, Feb. 2014.

[7] J. Niiranen, "Voltage dip ride through of doubly-fed generator equipped with active crowbar," in the Nordic Wind Power Conference,” pp. 1501-1507, 2004.

[8] J. Morren and S. W. H. Haan, "Ride-through of wind turbines with doubly-fed induction generator during a voltage dip,” IEEE Trans. Energy Convers., Vol. 47, No. 2, pp. 435-441, Feb. 2012.

[9] F. Sulla, J. Svensson, and O. Samuelsson, "Symmetrical and unsymmetrical short-circuit current of squirrel-cage and doubly-fed induction generators," Electric Power Systems Research, Vol. 81, No.7, pp. 1610-1618, Jul. 2011.

[10] Z. Honglin and Y. Geng, "Short circuit current characteristics of doubly fed induction generator with crowbar protection under different voltage dips," in Proc. the CSEE, Vol. 47, No. 2, pp. 184-191, Jan. 2009. (in Chinese)

[11] M. Mohseni, M. A. S. Masoum, and S. M. Islam, "Low and high voltage ride-through of DFIG wind turbines using hybrid current controlled converters," Electric
Power Systems Research, Vol. 81, No. 7, pp. 1456-1465, Jul. 2011.

[12] K. Vinothkumar and M. P. Selvan, "Novel scheme for enhancement of fault ride-through capability of doubly fed induction generator based wind farms," Energy Conversion and Management, Vol. 52, No. 7, pp. 2651-2658, Jul. 2011.

[13] J. Lopez, E. Gubia, and P. Sanchis, "Wind turbines based on doubly fed induction generator under asymmetrical voltage dips,” IEEE Trans. Energy Convers., Vol. 23, No. 1, pp. 321-329, Jan. 2008.

[14] J. Lopez, P. Sanchis, X. Roboam, and L. Marroyo, "Dynamic behavior of the doubly fed induction generator during three-phase voltage dips,” IEEE Trans. Energy Convers., Vol. 22, No. 3, pp. 9-17, Mar. 2007.

[15] J. Morren and S. W. H. de Haan, "Short-circuit current of wind turbines with doubly fed induction generator," IEEE Trans. Energy Convers., Vol.22, No. 1, pp. 174-180, Jan. 2007.

[16] R. N. Banu and D. Devaraj, "Multi-objective GA with fuzzy decision making for security enhancement in power system,” Applied Soft Computing, Vol.12, No. 9, pp. 2756-2764, Sep. 2012.

[17] W. Zhang and Y. Liu, "Multi-objective reactive power and voltage control based on fuzzy optimization strategy and fuzzy adaptive particle swarm," Electr Power Energy System, Vol. 30, No. 9, pp. 525-532, Nov. 2008.

[18] A. T. D. Perera, R. A. Attalage, K. K. C. .K. Perera, etal, "A hybrid tool to combine multi-objective optimization and multi-criterion decision making in designing standalone hybrid energy systems," Applied Energy, Vol. 107, pp. 412-425, Jul. 2013.

[19] K. Y. Lee, A. S. Yome, and J. H. Park, "Adaptive Hopfield neural networks for economic load dispatch," IEEE Trans. Power Syst, Vol. 13, No. 2, pp. 519-526, Feb. 1998.

[20] S. Cheng and M.-Y. Chen, "Multi-objective reactive power optimization strategy for distribution system with penetration of distributed generation," International Journal of Electrical Power \& Energy Systems, Vol. 62, pp. 221-228, Nov. 2014.

[21] E. Khorram and H. Zarei, "Multi-objective optimization problems with Fuzzy relation equation constraints regarding max-average composition," Mathematical and Computer Modelling, Vol. 49, No. 5-6, pp. 856-867, Mar. 2009.

[22] A. Thapara, D. Pandey, and S. K. Gaur, "Satisficing solutions of multi-objective fuzzy optimization problems using genetic algorithm,” Applied Soft Computing, Vol. 12, No. 8, pp. 2178-2187, Aug. 2012.

[23] L. Wang and C. Singh, "Balancing risk and cost in fuzzy economic dispatch including wind power penetration based on particle swarm optimization," Electric Power Systems Research, Vol. 78, No. 8, pp. 1361-1368, Aug. 2008.

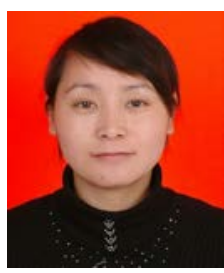

Wenjuan Zhang was born in Shaanxi, China. She received her B.S. degree in Automation Engineering, and her M.S. and Ph.D. degrees in Power Electronics and Electrical Drives from the Xi'an University of Technology, Shaanxi, China, in 2004, 2007 and 2011 , respectively. From 2007 to 2011, she was with Wind Power Generation Technology, 
Xi'an, China. In 2012, she joined the Baoji University of Arts and Sciences, Baoji, China, as an Associate Professor. Her current research interests include wind power generation, AC-AC converters, and PWM converter/inverter systems.

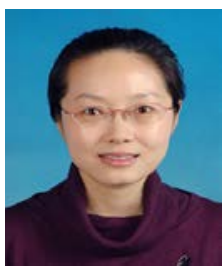

Haomiao Ma was born in Shaanxi, China. She received her B.S. degree in Electrical Engineering from the Hefei Technological University, Hefei, China, in 2000, her M.S. degree in Electrical Engineering from Xi'an Jiaotong University, Xi'an, China, in 2007, and her Ph.D. degree in Electrical Engineering from the Xi'an University of Technology, Shaanxi, China, in 2013. Since 2000, she has been with the School of Computer Science, Shaanxi Normal University, Xi'an, China, where she is presently working as an Associate Professor. Her current research interests include electronics, energy systems and signals.

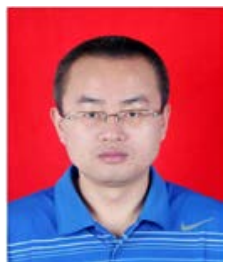

Junli Zhang was born in Shaanxi, China. He received his B.S. degree in Electrical Engineering from the Baoji University of Arts and Sciences, Baoji, China, in 2001, and his M.S. degree in Electrical Engineering from the Xi'an University of Technology, Shaanxi, China, in 2007. Since 2001, he has been with the Department of Electronic and Electrical Engineering, Baoji University of Arts and Sciences. He was a Teaching Assistant from 2001 to 2006, an Associate Professor from 2006 to 2011, and he is presently working as an Assistant Professor. His current research interests include new power electronic equipment and its application.

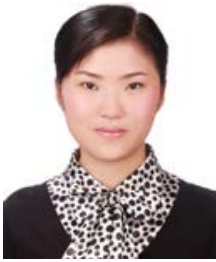

Lingling Chen was born in Sichuan, China. She received her M.S. degree in Electrical Engineering from the Xi'an University of Technology, Xi'an, China, in 2005, and her M.S. degree in Power Electronics and Electrical Drives from the Xi'an University of Technology, Shaanxi, China, in 2007. In 2008, she joined 94816 troop with the People's Liberation Army, China. Her current research interests include PWM converter/inverter systems.

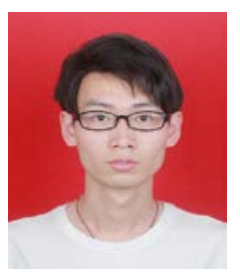

Yang Qu born in Shaanxi, China. He is presently working towards his B.S. degree in Automation Engineering at the Baoji University of Arts and Sciences, Baoji, China. 